BMJ Open

Sport \&

Exercise

Medicine

\title{
Weaker lower extremity muscle strength predicts traumatic knee injury in youth female but not male athletes
}

\author{
Sofia Ryman Augustsson, Eva Ageberg
}

To cite: Ryman

Augustsson S, Ageberg E. Weaker lower extremity muscle strength predicts traumatic knee injury in youth female but not male athletes. BMJ Open Sport Exerc Med 2017:3:e000222. doi:10.1136/bmjsem-2017000222

Accepted 1 March 2017

\section{CrossMark}

Department of Health Sciences, Musculoskeletal Function, Lund University, Lund, Sweden

Correspondence to Dr Sofia Ryman Augustsson; sofia.ryman_augustsson@ med.lu.se

\section{ABSTRACT}

Background The role of lower extremity (LE) muscle strength for predicting traumatic knee injury in youth athletes is largely unknown.

Aims The aim was to investigate the influence of LE muscle strength on traumatic knee injury in youth female and male athletes.

Methods 225 athletes (40\% females) from sport senior high schools in Sweden were included in this case-control study. The athletes recorded any traumatic knee injury that had occurred during their high-school period in a web-based injury form. A one repetition maximum (1RM) barbell squat test was used to measure LE muscle strength. The 1 RM was dichotomised to analyse 'weak' versus 'strong' athletes according to the median (weak median vs strong median ). Results 63 traumatic knee injuries, including 18 ACL injuries, were registered. The majority of injured female athletes were in the weak group compared with the strong group ( $p=0.0001)$. The odds of sustaining a traumatic knee injury and an ACL injury was 9.5 times higher and 7 times higher, respectively, in the weak $_{\text {median }}$ group compared with the strong median $_{\text {m }}$ group in females $(p \leq 0.011)$. A relative 1 RM squat $\leq 1.05 \mathrm{~kg}$ (105\% of bodyweight) was established as the best cut-off value to distinguish high versus low risk of injury in female athletes. No strength-injury relationships were observed for the male athletes $(p \geq 0.348)$.

Conclusions Weaker LE muscle strength predicted traumatic knee injury in youth female athletes, but not in males. This suggests that LE muscle strength should be included in injury screening in youth female athletes.

\section{BACKGROUND}

The rate of traumatic knee injury in sports remains high and is still an urgent priority. ${ }^{1}$ The risk profile for traumatic knee injury, such as injury to the ACL injury, appears multifactorial with several theories described in the literature. For example, increased knee valgus, high knee abduction loads and medial knee displacement are factors suggested to be associated with ACL injury. ${ }^{3-5}$ Plausible explanations for the higher rate of ACL injury in females compared with males have also been proposed, that is, worse

\section{What are the new findings?}

Female youth athletes with weaker lower extremity (LE) muscle strength, assessed with the one repetition maximum (1RM) barbell squat, were at higher risk of sustaining a traumatic knee injury compared with those with stronger muscles.

- The odds of sustaining a traumatic knee injury for weaker female athletes was 9.5 times higher compared with stronger females.

- There was no strength-injury relationship in youth male athletes.

How might it impact on clinical practice in the near future?

The 1RM barbell squat test may be used in the screening of knee injury risk in female youth athletes, with an $1 \mathrm{RM}$ relative value $\leq 1.05 \mathrm{~kg}$ used as a clinical cut-off for high-injury risk.

- Injury prevention programmes aimed to increase LE muscle strength may be an important modifiable factor to prevent knee injuries in youth female athletes.

- Modifiable risk factors for knee injury remain to be evaluated in male youth athletes.

neuromuscular control strategies cutting manoeuvres ${ }^{6}$ and lower hamstring to quadriceps torque ratios. ${ }^{7}$ However, the role of lower extremity (LE) muscle strength as a predictive factor for traumatic knee injury is still relatively unknown, and existing studies report contradictive results. In one study, lower hip muscle strength was found to be a risk factor for future non-contact ACL injury in athletes competing in various sports, ${ }^{8}$ whereas in another study, no relationship was observed between LE muscle strength and future ACL injury in female elite soccer players. $^{9}$

Previous studies on risk factors for traumatic knee injury mainly include adult athletes and often comprise only one gender or analyse 
data for men and women together. ${ }^{2} 489$ However, ACL injuries occur also during adolescence, particular in female athletes, ${ }^{10}{ }^{11}$ stressing the need to evaluate factors that contribute to knee injury risk in this population. To our knowledge, there are no studies on the relationship between LE muscle strength and the risk of traumatic knee injury, including ACL injury, among youth athletes. Such studies are important because muscle strength is a modifiable factor, which can improve by targeted training. Moreover, since LE muscle strength increases significantly less with age among females compared with males, ${ }^{12}$ it is important to evaluate females and males separately.

Therefore, the aim of the present study was to investigate the influence of LE muscle strength on traumatic knee injury in youth female and male athletes. We hypothesised that weaker LE muscle strength would be associated with a higher risk of traumatic knee injury.

\section{MATERIALS AND METHODS}

\section{Study design and procedure}

Data for this case-control study, adhering to the STROBE statement, ${ }^{13}$ were collected during 20132015. Coaches of 2144 athletes involved in sports related to high risk of knee injury, at 90 high schools (161 sport programmes) in Sweden, were contacted and

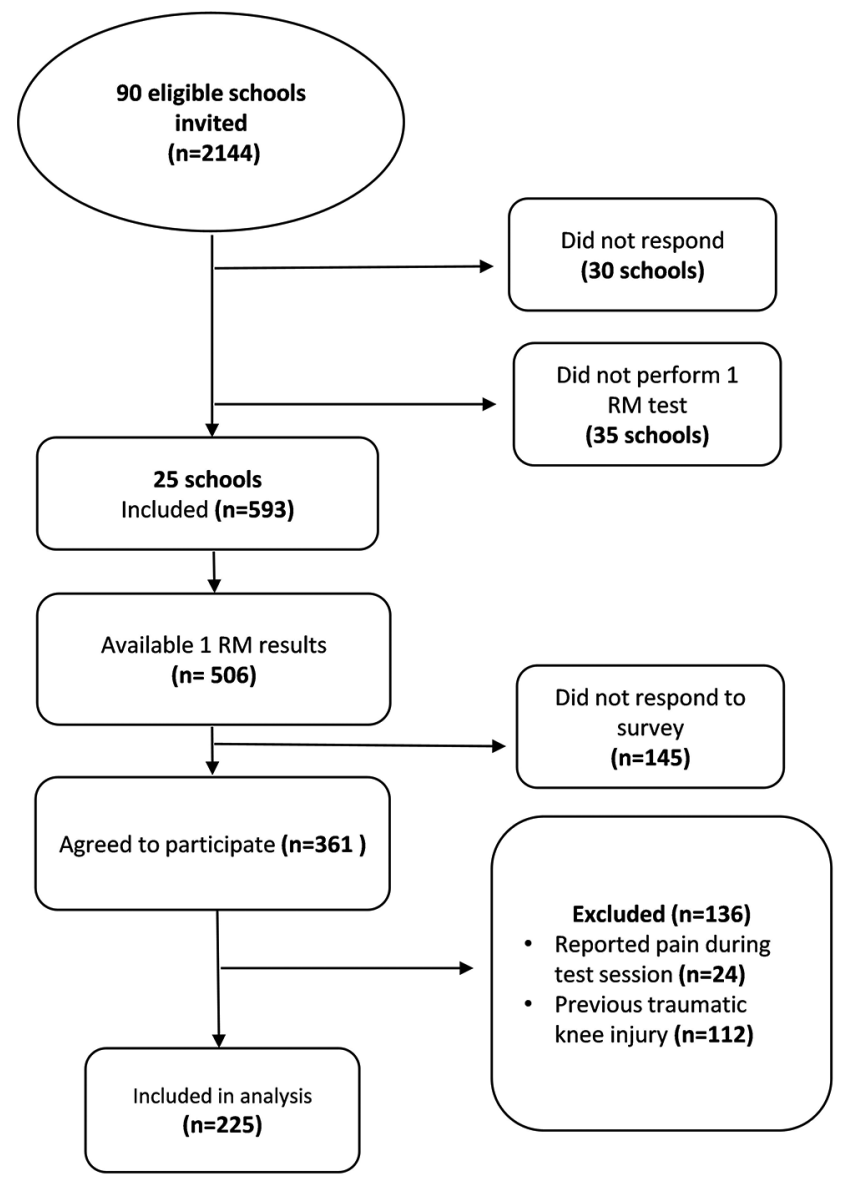

Figure 1 Flow chart of study participants. 1RM, one repetition maximum. introduced to the study through email (figure 1). The team coach at each school distributed a web-based form to the athletes during their first, second or third year of the high-school period by email or through the school's intra-net system. A reminder email was sent out if no response was received by the school team coach within 1-3 months. Once the form was completed, the athlete could not re-enter.

A one repetition maximum (1RM) barbell squat test, assessed during the athletes' first or second year by an instructor at each school, was used to measure LE muscle strength. This test is used as a part of 'Fysprofilen", which is a battery of tests developed on behalf of the Swedish Olympic Committee, and is frequently used for assessment of different aspects of physical performance in Swedish athletes. ${ }^{14}$

\section{PARTICIPANTS}

Inclusion criteria were male and female athletes, aged 15-19 years, participating and competing in ice hockey, handball, soccer, alpine skiing, basketball or floorball. Exclusion criteria were (1) athletes that did not perform the 1RM barbell squat test, (2) knee injury prior to 1RM test and (3) pain during the test session. Finally, 225 athletes were included in the analysis (figure 1 and table 1). Written information was given to each athlete and informed consent was obtained online.

A non-response analysis (independent sample $t$-test) was performed to compare the result of the $1 \mathrm{RM}$, between the non-participants $(n=145)$ and the participants $(n=225)$, and the gender distribution in each sport was compared with previous data. ${ }^{15} 16$ The mean difference for the 1RM absolute value between nonparticipants and participants was $3.7 \mathrm{~kg}(95 \% \mathrm{CI}-9.1$ to 2.4) for females and $2.4 \mathrm{~kg}$ (95\% CI -6.8 to 2.1$)$ for males, indicating no statistically significant or clinically relevant differences. The gender distribution in the present study ( $43 \%$ females) is in line with the gender distribution in each specific sport and age range in Sweden $(39 \%){ }^{15} 16$

\section{OUTCOME MEASURES}

\section{Injury registration}

The web-based form (Survey Monkey) was designed by the authors and was pilot-tested on youth athletes not included in the study, to obtain views about the design and to achieve face validity. A final version of the form was then constructed and used in the present study. The athletes recorded any traumatic knee injury that had occurred during their high-school period. A traumatic knee injury was defined as an injury to the ACL, other ligaments, menisci, cartilage damage or fracture. This definition was provided in the form. The form also included questions regarding the anatomical localization of the injury (left or right knee), date of sustaining the injury, any surgery, rehabilitation, as well as any injury/ complaints during the 1RM test session. 
Table 1 Participant characteristics for female and male athletes $(n=225)$

\begin{tabular}{lcc}
\hline & Females (n=89) & Males $(\mathbf{n}=\mathbf{1 3 6})$ \\
\hline Age (years) & $17(1)$ & Mean (SD) \\
\hline Height $(\mathrm{cm})$ & $170(6.5)$ & $182(10.1)$ \\
\hline Weight $(\mathrm{kg})$ & $66(6.7)$ & $81(10.4)$ \\
\hline Years of competition & $10(2.5)$ & $10(2.4)$ \\
\hline Training hours/week & $12.3(5)$ & $11.5(3.5)$ \\
\hline Sport affiliation & $\%$ & $\%$ \\
\hline lce hockey & 2 & 7 \\
\hline Handball & 47 & 42 \\
\hline Soccer & 10 & 18 \\
\hline Alpine skiing & 10 & 16 \\
\hline Basketball & 22 & 16 \\
\hline Floorball & 9 & \\
\hline
\end{tabular}

\section{Muscle strength test}

The 1RM barbell squat test is a measure of maximum muscular strength of the thigh and hip muscles (quadriceps, the gluteus muscles, hamstrings and hip adductors $)^{17}$ and the relative $1 \mathrm{RM}, 1 \mathrm{RM}$ value expressed relative to bodyweight (r1RM), was used. The 1RM barbell squat was performed according to Fysprofilen.$^{14}$ All athletes were tested by well-educated instructors. This test has high inter-rater reliability $\left(\mathrm{ICC}_{2,1}=0.85\right.$, SEM 6.9). ${ }^{18}$

\section{STATISTICAL ANALYSIS}

Statistics were calculated using IBM SPSS (IBM SPSS Statistics for Windows, Version 23.0. IBM, Armonk, NY). The primary outcome was the rate of traumatic knee injury, and the secondary outcome was the rate of ACL injury. The level of significance was set at $\mathrm{p} \leq 0.05$. The strength variable was dichotomised to analyse 'weak' versus 'strong' athletes according to the median (weak median vs strong $\left.{ }_{\text {median }}\right)$, and, when possible, the lower (25') and upper $\left(75^{\prime}\right)$ quartiles (weak quartile $_{\text {vs }}$ strong $_{\text {quartile) }}$ ). The Fisher's exact test was used to assess the association between muscle strength (r1RM) at baseline (weak vs strong) and the outcome of sustaining a knee injury (yes/ no). OR with $95 \%$ CI was calculated to estimate the magnitude of muscle strength as a risk factor for injury. The binary logistic regression was used to verify whether muscle strength (r1RM) had a significant impact on the risk of knee injury. Receiver operating characteristic (ROC) curves were constructed to determine the discriminative accuracy of the $\mathrm{rlRM}$ to predict traumatic knee injury, and the optimal clinical cut-off value for classifying high versus low risk of injury. The overall accuracy of the strength test was measured by evaluating the area under the curve (AUC), ranging from 0 to 1 . The optimal clinical cut-off point for the muscle strength measurement was selected by maximising sensitivity and specificity across various cut-off points. The independent sample $t$ test was used to compare means in injury prevalence between gender.

Based on results from previous studies, ${ }^{2} 19$ we estimated that about $10 \%$ would suffer a traumatic knee injury and $2 \%$ of the athletes would suffer an ACL injury. A preliminary sample size calculation, using these data, indicated that approximately 450 athletes would be needed in each group (weak median $_{\text {and strong }}$ median, respectively) to detect a $50 \%$ difference in injury prevalence between weak and strong athletes, with a power of $0.80(\alpha=0.05)$. When 150 participants were included, a new sample size calculation with empirical data was performed. As the prevalence of traumatic knee injury was $30 \%$, this second sample size calculation indicated that approximately 260 athletes $(n=130$ in the weak median $_{\text {and strong }}$ median groups, respectively) were required to detect a $50 \%$ difference in the odds of outcome between the weak $k_{\text {median }}$ and strong ${ }_{\text {median }}$ groups for females and males, respectively.

\section{RESULTS}

\section{Injury data}

There were 63 traumatic knee injuries registered (table $2)$, with a higher prevalence in female $(42 \%)$ than male athletes $(21 \%)(p=0.006)$. Eighteen were ACL injuries

Table 2 Characteristics of traumatic knee injuries reported by participants $(n=52)$

\begin{tabular}{lc}
\hline Characteristics & $\mathbf{n}(\%)$ \\
\hline Female, $\mathrm{n}$ & $26(50)$ \\
\hline Injured knee & \\
$\quad$ Left & $20(31)$ \\
Right & $35(56)$ \\
\hline Bilateral & $8(13)$ \\
\hline Type of knee injury & \\
\hline Traumatic knee injury* & 63 \\
\hline ACL injury & $18(29)$ \\
\hline Isolated & $5(28)$ \\
\hline Concomitant injuries ${ }^{\dagger}$ & $13(72)$ \\
\hline Reinjury & $3(17)$ \\
\hline Treatment & \\
\hline Rehabilitation & $60(95)$ \\
\hline Reconstructive ACL surgery & $9(50)$ \\
\hline Revision reconstructive surgery & $1(6)$ \\
\hline
\end{tabular}

${ }^{*} \mathrm{ACL}$, other ligaments, menisci, cartilage damage or fracture. $\dagger$ Meniscus $(n=10)$, collateral ligament injury $(n=1)$, several associated injuries $(n=2)$. 
Table 3 Injury and muscle strength characteristics according to gender and strength groups $(n=225)$

\begin{tabular}{|c|c|c|c|c|c|}
\hline $\begin{array}{l}\text { Strength groups } \\
\text { Median }\end{array}$ & $\begin{array}{l}\text { r1RM } \\
\text { Mean (SD) }\end{array}$ & $\begin{array}{l}\text { Traumatic injury } \\
\mathbf{n}\end{array}$ & OR (95\% Cl) & $\begin{array}{l}\text { ACL injury } \\
n\end{array}$ & OR (95\% Cl) \\
\hline Weak $_{\text {median }}$ females $(n=45)$ & $0.9(0.15)$ & 22 & 9.56 (2.93 to 31.20$)$ & 12 & $7.64(1.60$ to 36.52$)$ \\
\hline Strong $_{\text {median }}$ females $(n=44)$ & $1.3(0.2)$ & 4 & & 2 & \\
\hline Weak $_{\text {median }}$ males $(n=68)$ & $1.16(0.18)$ & 13 & $0.90(0.38$ to 2.31$)$ & 3 & 0.30 (0.03 to 2.91$)$ \\
\hline Strong $_{\text {median }}$ males $(n=68)$ & $1.6(0.1)$ & 13 & & 1 & \\
\hline Quartiles* & & & p value ${ }^{\dagger}$ & & \\
\hline Weak $_{\text {quartile }}$ females $(n=22)$ & $0.78(0.1)$ & 9 & $p=0.044$ & 6 & - \\
\hline Strong $_{\text {quartile }}$ females $(n=22)$ & $1.48(0.2)$ & 3 & & 1 & \\
\hline Weak $_{\text {quartile }}$ males $(n=34)$ & $0.98(0.1)$ & 4 & $p=1.000$ & 0 & - \\
\hline Strong $_{\text {quartile }}$ males $(n=34)$ & $1.75(01)$ & 4 & & 1 & \\
\hline
\end{tabular}

Number of injured athletes, mean (SD) for relative (kg/bodyweight) 1RM barbell squat together with OR, and $\mathrm{p}$ value for Fisher's exact test, are presented.

*Upper versus lower quartile.

$\dagger$ Fisher's exact test.

r1RM, one repetition maximum.

giving an overall ACL injury prevalence of $8 \%$, which was higher in females (17\%) than males (2\%) $(\mathrm{p}=0.001)$.

\section{Influence of lower extremity (LE) muscle strength on traumatic knee injury}

The majority of injured females were in the weak $_{\text {median }}$ group $(\mathrm{n}=22)$ compared with the strongmedian group $(n=4) \quad(p=0.0001)$, while there were no differences between the weak median $(\mathrm{n}=13)$ and strong $\mathrm{m}_{\text {median }}$ $(\mathrm{n}=13)$ groups for males $(\mathrm{p}=0.830)$ (table 3 and figure 2). The injury prevalence was higher in weak females (0.66 injuries/athlete) than in weak males (0.19 injuries/athlete) $(\mathrm{p}<0.0001)$, whereas there was no gender difference for strong athletes $(\mathrm{p}=0.317)$. The odds of sustaining a traumatic knee injury was 9.5 times higher

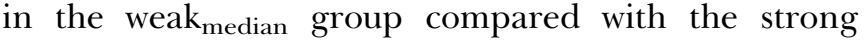

median group of female athletes $(\mathrm{p}=0.0001)$, whereas this relationship was not found for the male athletes $(\mathrm{p}=0.486)$ (table 3$)$. In addition, the binary logistic regression showed that the odds for having a knee injury decreased when muscle strength increased (OR $0.086 ; 95 \%$ CI 0.012 to $0.631 ; \mathrm{p}=0.016$ ).

For the quartiles, most injured females were in the

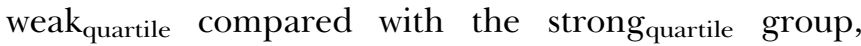
while there were no differences between the groups of males (table 3 ).

The ROC curve analysis identified a r1RM squat $\leq 1.05 \mathrm{~kg}$ (105\% of bodyweight) as the best cut-off value to distinguish female athletes who sustained a traumatic knee injury and those who remained non-injured (AUC $=0.71(95 \%$ CI 0.59 to 0.83$), p=0.002)$. The cutoff value of 1.05 corresponded to a sensitivity of $77 \%$ and a specificity of $71 \%$ (figure 3 ).

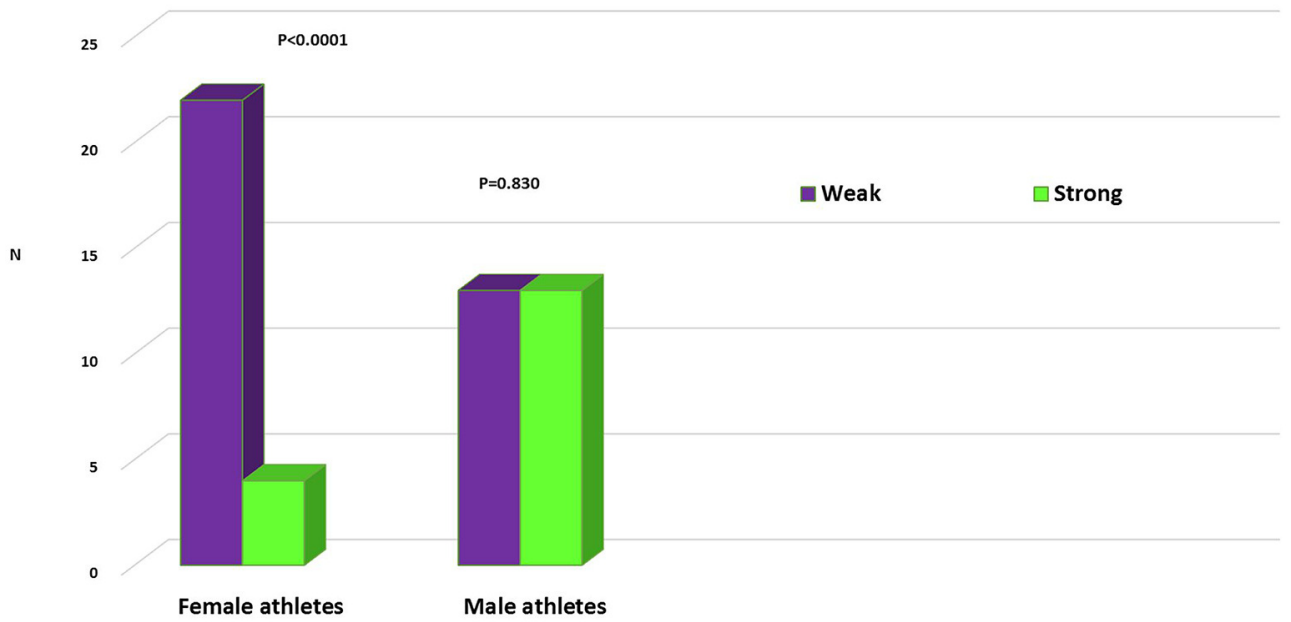

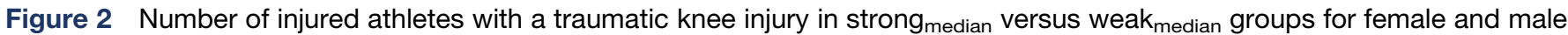
athletes. 


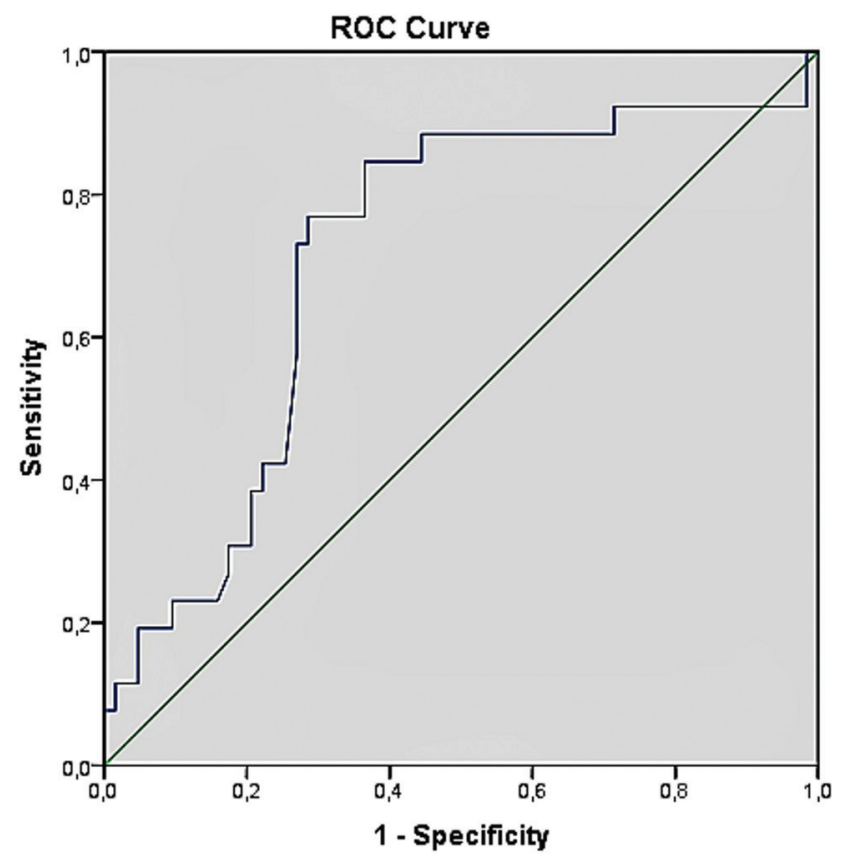

Figure 3 Area under the receiver operating characteristic (ROC) curve indicating a one repetition maximum squat $\leq 1.05 \mathrm{~kg}$ being the optimal clinical cut-off for distinguishing high versus low risk of injury in female athletes.

\section{Influence of LE muscle strength on ACL injury}

Most injured females were in the weak $_{\text {median }}(n=12)$ compared with the strongmedian group $(n=2)$ $(p=0.007)$, while there were no differences between the weak $_{\text {median }}(n=1)$ and strong $g_{\text {median }}(n=3)$ groups in the male athletes $(\mathrm{p}=0.348)$ (table 3 and figure 3$)$. The weak females had significantly higher rates of ACL injury than weak males $(p=0.001)$, whereas there was no gender difference for strong athletes in the rate of ACL injury $(p=0.364)$ (figure 3$)$. The odds of sustaining an ACL injury was seven times higher in the weak $_{\text {median }}$ group compared with the strong $_{\text {median }}$ group of female athletes $(p=0.011)$, whereas this relationship was not observed for the male athletes $(\mathrm{p}=0.348)($ table 3$)$.

\section{DISCUSSION}

The main results of the present study were that weaker LE muscle strength was associated with a higher risk of traumatic knee injury, including ACL injury, in youth female athletes but not in males. We observed a 9.5 times higher odds of sustaining an injury among weak female athletes compared with strong females. Hence, weaker levels of LE muscle strength may be one important, and modifiable, risk factor for sustaining a traumatic knee injury in youth female athletes (figure 4).

\section{Weaker LE muscle strength risk factor for knee injury in youth female athletes}

Our results indicate that weaker LE muscle strength is a risk factor for traumatic knee injury in females. In support of this, the binary logistic regression showed that the odds for having a knee injury was lower with greater muscle strength. Furthermore, the ROC curve analysis indicated that an rlRM squat strength $\leq 1.05 \mathrm{~kg} /$ bodyweight increased the risk of injury in female athletes. In line with our findings, Khayambashi et $a l^{8}$ reported in a case-control study that weaker muscle strength was associated with a higher risk of ACL injury in 20-year-old athletes. When data were collapsed across sex, non-injured athletes had significantly greater hip external rotation and hip abduction strength compared with injured athletes. However, no strength-injury relationship was presented for females and males separately. ${ }^{8}$

In contrast to our findings, a Norwegian study ${ }^{9}$ did not observe any relationship between strength and knee injury in elite female soccer players. One reason for the differences between our study and the Norwegian study could be derived from the measurements of muscle strength. They tested athletes for dynamic muscle strength with a test of $1 \mathrm{RM}$ during a seated leg press, ${ }^{9}$

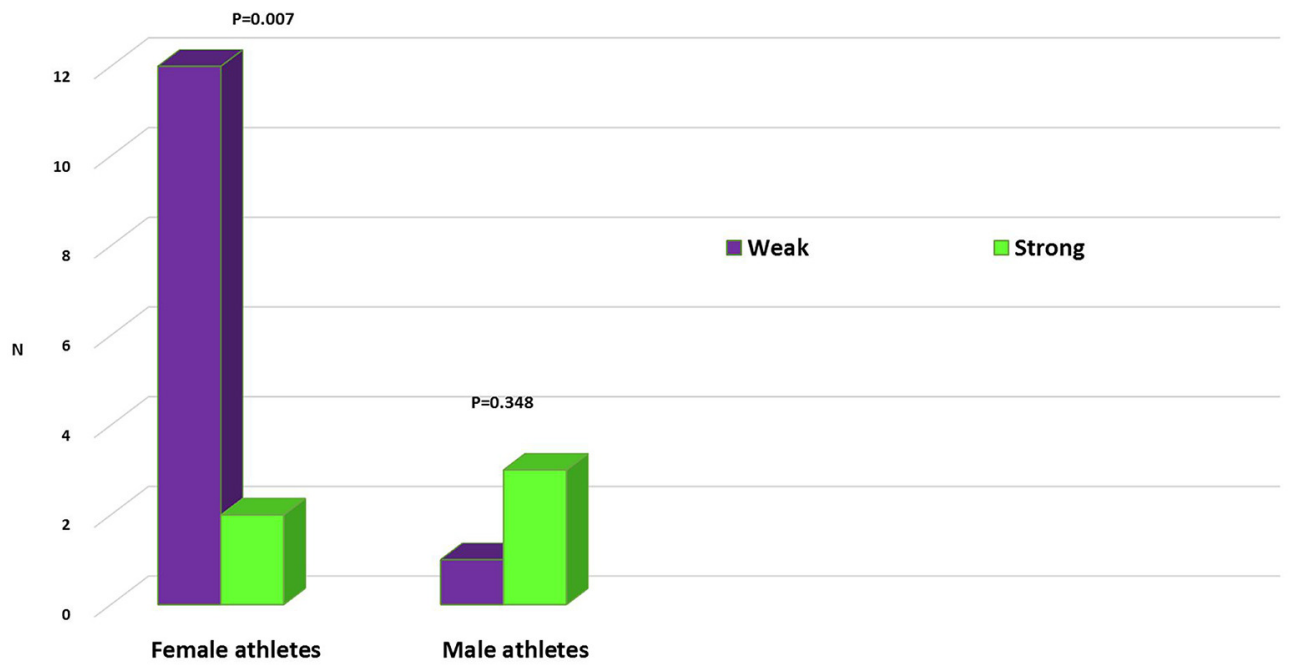

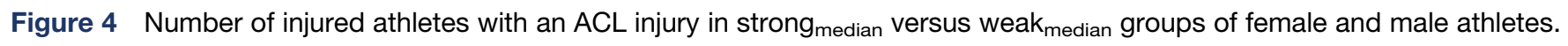


while we used a barbell squat test. Both the barbell squat and the leg press tests target the LE in a closed-kinetic chain position. However, compared with a seated leg press, a free barbell squat generates greater quadriceps and hamstrings activity, ${ }^{20}$ and challenges the neuromuscular system of the prime movers to a greater extent. ${ }^{21}$ Another possible reason for the contrasting findings could be due to the included population. Nilstad et $a l^{9}$ included adult elite female athletes, whereas we included youth athletes. In general, adult elite athletes are already at a high level of physical performance, including muscle strength, compared with non-elite youth athletes. In a recent International Olympic Committee consensus statement, the authors argued that participation in organised sports does not alone ensure appropriate levels of strength and neuromuscular capacity to sufficiently meet the physical demands of sports. ${ }^{22}$ Although improvements in performance can be attained to a certain degree in youth, the full development of a specific skill and muscle strength depends on full maturation of the nervous system. ${ }^{23}$ Muscle strength improves until full maturity is reached; usually by age 20 in women and between the ages 20 and 30 in men. ${ }^{23}$ Hence, it could be that the level of muscle strength influences knee injury risk in youth female athletes, but not in females who have reached maturity and elite level. Injury risk factors in youth may differ from those in adults and, therefore, injury risk screening may need to be adjusted depending on the age of the target population.

\section{Aspects of gender differences}

Our hypothesis that weaker LE muscle strength was associated with future traumatic knee injury, and ACL injury, was confirmed for female athletes, but not for males. There may be several explanations for this gender difference. It has been suggested that muscle strength, in terms of lower hamstring to quadriceps torque ratio, is a risk factor for ACL injury in female but not in male athletes. ${ }^{7}$ Also, LE muscle strength increases significantly less with age among youth females compared with youth males. ${ }^{12}{ }^{24}$ Furthermore, gender differences have been reported for muscle activation patterns during side-cutting manoeuvres, possibly providing inadequate joint protection and stability in females. ${ }^{6}$ Another gender-related factor is that muscle fatigue increases knee abduction moment during a drop jump to a greater extent in young female athletes compared with male athletes; a factor thought to be associated with the higher risk of ACL injuries observed in women than in men. ${ }^{25}$

Taken together, muscle function features such as muscle strength, endurance and neuromuscular control appear to differ between genders. These factors may be especially important to consider for preventing knee injury in young female athletes, whereas other factors may be more important for males. Hence, the findings from our study and previous studies suggest that injury screening for modifiable factors such as muscle strength, and injury prevention training including LE strength, is needed in female youth athletes.

\section{Injury in youth athletes}

The rate of ACL injury seems to have increased in children and adolescents over the past couple of decades ${ }^{26-28}$ with the greatest risk seen in female high-school soccer and basketball players. ${ }^{29}$ One explanation for this could be due to the increased demands on young athletes with an increasing trend in sports specialisation already during childhood. $^{22}$ 30-33 This, together with less spontaneous physical activity, might have a negative effect on children's body tissue that may not be prepared for the required load. Optimal recovery between practice/matches is crucial for neuromuscular and strength improvements, and to avoid excessive musculoskeletal stress and risk of injury. ${ }^{23}$ In the present study, we found no differences between females and males for number of training hours. However, we did not have data for the number of total exposure hours. It has been a concern that talented young female soccer players frequently play additional matches with other teams than their own and with a team at a senior level with older, more physically matured and skilled opponents, putting them at a higher injury risk. ${ }^{34}$ It has also been recognised that soccer athletes playing two matches with a maximum of 4 days recovery between matches, compared with one match per week, increases the risk of injury. ${ }^{35}$ Hence, the issue of load management in youth athletes should be taken in consideration and be further investigated in youth athletes.

\section{Strengths and limitations}

The main strength of the present study is that the sample consisted of a homogeneous group of athletes, within the same age, at high-school sport programmes, and involved in high-risk sports. Another strength is that the gender distribution is similar to that presented in each specific sport and age range in Sweden, suggesting that the present study provides a typical representation of these athletes. Some limitations in the present study need to be acknowledged. First, traumatic knee injury was reported by the athletes rather than by a more valid approach such as acquiring data from medical records. In the injury section of the form, we asked specifically about traumatic injury, including a definition of such injury. Due to the nature of a traumatic injury, with pain, functional limitations and inability to participate in sports, it is likely that the athletes did recall such an injury. Thus, an underestimation of injuries was likely not present, although the presence of any overestimation is difficult to value. Second, data from the 1RM test were collected retrospectively, possibly affecting reliability. Although good reliability has been reported for this test, ${ }^{18}$ no inter-rater reliability data were collected in the present study. However, the 1RM squat was assessed by experienced instructors, all had taken the same education, and they all followed the test procedure of Fysprofilen. The barbell squat is widely used in sports, easily used in various 
settings and is thought to be a functional exercise relevant to movements in several sports. ${ }^{36-38}$ Still, a possible disadvantage of the squat test could be the difficulty to distinguish the relative contribution of factors (ie, LE and trunk strength, flexibility, neuromuscular and postural control) to failure in the squat test and, thus, to predict injury. Third, although there were no differences in 1RM absolute value between responders and non-responders, we cannot exclude that some of the non-responders may have had a knee injury possibly affecting the strength results.

\section{CONCLUSIONS}

Weaker LE muscle strength predicted future traumatic knee injury in youth female athletes, but not in males. This suggests that LE muscle strength should be included in injury screening in youth female athletes. Intervention studies are needed to evaluate whether improvements in LE muscle strength can be obtained and thereby reduce the risk of traumatic knee injury in this population.

Acknowledgements The authors thank the contact persons at the national sport programmes for distributing the injury form and for providing muscle strength data. The authors also like to thank Tommy Schyman for his valuable guidance with the statistics.

Contributors SRA and EA were responsible for the planning, conception and design of the study. SRA was responsible for data collection and data analyses. Both authors were involved in the interpretation of the data and in manuscript writing, and approved the final version.

Funding This study was supported by grants from Swedish Research Council for Sport Science, the Free Professional Support Fund from The Swedish Association of Physiotherapists, the Crafoord foundation, and the Faculty of Medicine Lund University.

Competing interests None declared.

Ethics approval The study was approved by the Ethics Committee at the University of Gothenburg, Sweden (EPN no 929-13)

Provenance and peer review Not commissioned; internally peer reviewed.

Open Access This is an Open Access article distributed in accordance with the Creative Commons Attribution Non Commercial (CC BY-NC 4.0) license, which permits others to distribute, remix, adapt, build upon this work noncommercially, and license their derivative works on different terms, provided the original work is properly cited and the use is non-commercial. See: http:// creativecommons.org/licenses/by-nc/4.0/

(C) Article author(s) (or their employer(s) unless otherwise stated in the text of the article) 2017. All rights reserved. No commercial use is permitted unless otherwise expressly granted.

\section{REFERENCES}

1. Nordenvall R, Bahmanyar S, Adami J, et al. A population-based nationwide study of cruciate ligament injury in Sweden, 2001-2009: incidence, treatment, and sex differences. Am J Sports Med 2012;40:1808-13.

2. Waldén $M$, Hägglund $M$, Magnusson $\mathrm{H}$, et al. Anterior cruciate ligament injury in elite football: a prospective three-cohort study. Knee Surg Sports Traumatol Arthrosc 2011;19:11-19.

3. Hewett TE, Myer GD, Ford KR, et al. Biomechanical measures of neuromuscular control and valgus loading of the knee predict anterior cruciate ligament injury risk in female athletes: a prospective study. Am J Sports Med 2005;33:492-501.

4. Krosshaug $\mathrm{T}$, Steffen $\mathrm{K}$, Kristianslund $\mathrm{E}$, et al. The vertical drop jump is a poor screening test for ACL injuries in female elite soccer and handball players: a prospective cohort study of 710 athletes. Am J Sports Med 2016;44:874-83.

5. Waldén M, Krosshaug T, Bjørneboe J, et al. Three distinct mechanisms predominate in non-contact anterior cruciate ligament injuries in male professional football players: a systematic video analysis of 39 cases. Br J Sports Med 2015;49:1452-60.

6. Landry SC, McKean KA, Hubley-Kozey CL, et al. Gender differences exist in neuromuscular control patterns during the pre-contact and early stance phase of an unanticipated side-cut and cross-cut maneuver in 15-18 years old adolescent soccer players. $J$ Electromyogr Kinesiol 2009;19:e370-e379.

7. Myer GD, Ford KR, Barber Foss KD, et al. The relationship of hamstrings and quadriceps strength to anterior cruciate ligament injury in female athletes. Clin J Sport Med 2009;19:3-8

8. Khayambashi K, Ghoddosi N, Straub RK, et al. Hip muscle strength predicts noncontact anterior cruciate ligament injury in male and female athletes: a prospective study. Am J Sports Med 2016;44:355-61.

9. Nilstad A, Andersen TE, Bahr R, et al. Risk factors for lower extremity injuries in elite female soccer players. Am J Sports Med 2014:42:940-8

10. Hägglund $M$, Waldén $M$. Risk factors for acute knee injury in female youth football. Knee Surg Sports Traumatol Arthrosc 2016;24:737-46.

11. Clausen MB, Zebis MK, Møller M, et al. High injury incidence in adolescent female soccer. Am J Sports Med 2014;42:2487-94.

12. Barber-Westin SD, Noyes FR, Galloway M. Jump-land characteristics and muscle strength development in young athletes: a gender comparison of 1140 athletes 9 to 17 years of age. Am $J$ Sports Med 2006;34:375-84.

13. STROBE statement. $2007 \mathrm{http}: / /$ www.strobe-statement.org/?id= available-checklists (accessed Jul 2016).

14. Fysprofilen ${ }^{\mathrm{TM}}$ http://fysprofilen.se/sv/default.aspx?PagelD=10662016 (accessed Nov 2016).

15. Riksidrottsförbundet. Idrotten i siffror. http://www.rf.se/globalassets/ riksidrottsforbundet/dokument/jamstalldhet/idrotten-i-siffrorjamstalldhet.pdf2014 (accessed July 2016).

16. Riksidrottsförbundet. Lokalt aktivitetsstöd ̊̊. 2011-2014 http://www. rf.se/globalassets/riksidrottsforbundet/dokument/jamstalldhet/lokjamstalldhet.pdf.2014 (accessed Jul 2016).

17. Bryanton MA, Carey JP, Kennedy MD, et al. Quadriceps effort during squat exercise depends on hip extensor muscle strategy. Sports Biomech 2015;14:122-38.

18. Ryman Augustsson S, Svantesson U. Reliability of the 1 RM bench press and squat in young women. Eur J Physiother 2013;15:118-26.

19. Snellman K, Parkkari J, Kannus $P$, et al. Sports injuries in floorball: a prospective one-year follow-up study. Int J Sports Med 2001;22:531-6.

20. Escamilla RF, Fleisig GS, Zheng N, et al. Effects of technique variations on knee biomechanics during the squat and leg press. Med Sci Sports Exerc 2001;33:1552-66.

21. Clark DR, Lambert MI, Hunter AM. Muscle activation in the loaded free barbell squat: a brief review. J Strength Cond Res 2012;26:1169-78.

22. Bergeron MF, Mountjoy M, Armstrong N, et al. International olympic committee consensus statement on youth athletic development. $\mathrm{Br}$ $J$ Sports Med 2015;49:843-51.

23. Kenney WL, Wilmore JH, Costill DL. Physiology of sport and exercise. Sixth edition. Champaign, IL: Human Kinetics 2015

24. Brent JL, Myer GD, Ford KR, et al. The effect of sex and age on isokinetic hip-abduction torques. J Sport Rehabil 2013;22:41-6.

25. McLean SG, Fellin RE, Felin RE, Suedekum N, et al. Impact of fatigue on gender-based high-risk landing strategies. Med Sci Sports Exerc 2007;39:502-14.

26. Beck NA, Lawrence JT, Nordin JD, et al. ACL tears in School+Aged Children and Adolescents: Has There Been an Increased Incidence over the Last 20 Years? Washington, DC: American Academy of Pediatrics (AAP) National Conference \& Exhibition.

27. Werner BC, Yang S, Looney AM, et al. Trends in pediatric and adolescent anterior cruciate ligament injury and reconstruction. $J$ Pediatr Orthop 2016;36:447-52.

28. Dekker TJ, Rush JK, Schmitz MR. What's new in pediatric and adolescent anterior cruciate ligament injuries? J Pediatr Orthop 2016:1.

29. Gornitzky AL, Lott A, Yellin JL, et al. Sport-Specific yearly risk and incidence of anterior cruciate ligament tears in high school athletes: a systematic review and Meta-analysis. Am J Sports Med 2016;44:2716-23. 
30. Lund S. De önskade och oönskade specialidrottseleverna. 3, 2011:18-20.

31. Jayanthi N, Pinkham C, Dugas L, et al. Sports specialization in young athletes: evidence-based recommendations. Sports Health 2013;5:251-7.

32. Malina RM. Early sport specialization: roots, effectiveness, risks. Curr Sports Med Rep 2010;9:364-71.

33. Kristiansen E, Stensrud T. Young female handball players and sport specialisation: how do they cope with the transition from primary school into a secondary sport school? Br J Sports Med 2017;51:58-63.

34. Söderman $\mathrm{K}$, Pietilä $\mathrm{T}$, Alfredson $\mathrm{H}$, et al. Anterior cruciate ligament injuries in young females playing soccer at senior levels. Scand J Med Sci Sports 2002;12:65-8.
35. Soligard $\mathrm{T}$, Schwellnus $\mathrm{M}$, Alonso $\mathrm{JM}$, et al. How much is too much? (Part 1) International olympic committee consensus statement on load in sport and risk of injury. $\mathrm{Br} J$ Sports Med 2016;50:1030-41.

36. McBride JM, Blow D, Kirby TJ, et al. Relationship between maximal squat strength and five, ten, and forty yard sprint times. J Strength Cond Res 2009;23:1633-6.

37. Augustsson SR. Maximum strength in squats determines jumping height in young female volleyball players. Open Sports Sci J 2013;6:41-6.

38. Wisløff U, Castagna C, Helgerud J, et al. Strong correlation of maximal squat strength with sprint performance and vertical jump height in elite soccer players. Br J Sports Med 2004;38:285-8. 